knowledge and the command over the conditions of life has also been extremely uneven. Our powers over inorganic Nature are much greater than our powers over life, mind and society; and since the former may be used for purposes of destruction, there is danger that before mankind has acquired sufficient knowledge of the causes of social change, and sufficient moral wisdom to use it aright, the whole structure may be wrecked, and the work of organizing mankind may have to be begun all over again. Scale of organization is of especial importance at the present time.

Self-development even on the part of large communities is becoming more difficult and precarious. This infinitely complicates the problem of reconciling order with freedom. Both logical and historieal analysis suggest that efficient control over the forces of external Nature and of the inner nature of man must rest upon an organization on a world scale, and must rely on methods which can call forth the spontaneous responses of all its members in the service of ends they can recognize as common.
Social Pathology. This brings out the complexity of social causation and the importance of bringing together the results of different modes of investigating and interpreting social phenomena. Taking one example only, the study of cause of crime has to be approached by way of broad social and economic studies, such as (1) correlating various types of crime with social and economic variables, such as price-rate of commodities, density of population, rural and urban conditions of life, etc.; (2) genetic studies; and (3) individual case-study, to which belong therapeutic methods of psychopathology. So little has been done to view the facts in relation one to another, that at different times undue prominence has been given to one or other factor in the causation of crime. To the sociologist taking a broad view it is clear that no invariant relation can be established between any single factor and crime, while these factors in themselves are complex and by no means independent. There are signs that the sociological method of approach is beginning to influence the study of crime both in Great Britain and in the United States.

\title{
Agricultural Research in India*
}

$\mathrm{T}$ HE Imperial Council of Agricultural Research was set up as a result of the Royal Commission on Agriculture in India in 1926. One of the conditions laid down was that the Council's activities should be periodically reviewed by some disinterested expert, and in 1936 Sir John Russell was invited to make an extensive tour of the provinces with this end in view, in so far as plant industry was concerned.

Sir John's report has now been published. The volume is divided into two parts, the first of which describes the type of agriculture, the crops and the factors which make for improvement in their yield, the special difficulties confronting Indian agriculture and the machinery for dealing with them. In the second part of the report, the various research schemes fostered by the Council and in progress throughout the country are described in detail.

Agriculture in India is not merely an industry but also the mode of life of a large part of the population, and in consequence the scope of the Council's activi. ties is of a far-reaching nature. Village improvement is in fact an essential preliminary to any fundamental advance in agriculture. The gulf that separates the experiment stations and the few large-scale farmers from the peasants, who cultivate the largest proportion of the land, needs to be bridged, and this is rendered peculiarly difficult to effect owing to the absence of the educated middle class farmers, who form such an important section of the farming community of the West.

A vast amount of pioneering work has been successfully accomplished by the Council since its formation, and the necessary extension now lies in the co-ordination of theory with practice, that is, work in the field rather than in the laboratory, increased productiveness being always the central problem. The great increase in the area under cash * Report on the Work of the Imperial Council of Agricultural
Research in Applying Science to Crop Production in India. (Delhi : Manager of Publications, 1937.) crops such as cotton, sugar cane and tea, compared with that under food crops, is one of the most remarkable features of modern Indian agriculture, and although much progress has been made both in their production and utilization, particularly in the case of sugar cane, greater co-operation with the buyers is desirable. Advances in this direction have already been made in the case of cotton and tea, as each crop has its own research station, which is in touch with the appropriate buyers. Similarly, work on food crops needs to be carried out in association with nutrition experts, and inquiries made into the possibilities of extending dairy husbandry and fruit and vegetable growing, if diet is to be raised to a more satisfactory level.

In view of the supreme importance of water supply, the establishment of a separate research institute for the study of irrigation and water relationships between soil and crops is deemed desirable. The proper unification of dry farming schemes is, of course, equally important. Questions concerning soil erosion and alkali trouble might well be dealt with by a soil conservation committee, which could also usefully collect and collate results of manurial trials and soil analyses. Similarly, matters relating to crop planning schemes and insect and fungus pests might be in the hands of a crop production committee, which would provide a convenient central body for co-ordination. Special problems such as locust control, on the other hand, need their own organization, and in spite of the fact that invasions only occur sporadically, a permanent service seems eminently desirable, so that immediate action may be taken when the need arises. The Imperial Agricultural Research Institute recently opened at New Delhi will, no doubt, play a specially important part in the co-ordination of the Council's schemes, and its programme be largely determined by the most pressing problems of the moment. A number of questions to which it could usefully give attention are suggested in the report. 
During his tour, Sir John Russell visited more than forty experiment stations and inspected nearly ninety research schemes, in most cases discussing the work with the individual in charge. The posts under the Council's schemes are of temporary nature only and a plea is made for the provision of a number of permanent appointments, to be filled gradually by selected investigators of proved ability. By this means, specially experienced men would be available to deal with difficult problems at the various stations, where local resources were inadequate. Such a scheme would inevitably necessitate an increase in the financial grant made to the Council, but the return in enhanced efficiency would seem to justify this.

Much of the research in agricultural science in India is not so widely known as it deserves to be, due largely to the practice of publishing results in a number of small communications. The preparation of a series of monographs by competent persons is suggested, setting forth the results obtained by Indian workers and pointing out how they differ from those obtained elsewhere. Such publications would greatly raise the prestige of Indian research work and also prove of value to teachers and research workers throughout India itself.

\section{Radio Transmission and the Ionosphere}

$\mathrm{M}$ ARCONI'S discovery that radio waves followed the curvature of the earth indicated that the signals were reflected back to earth by an electrified condition of the upper atmosphere. In 1925 Prof. E. V. Appleton in England and Breit and Tuve of the Carnegie Institution (U.S.A.) gave definite experimental demonstrations of the existence of such a mirror.

Since these experiments were made, research on the electrified region of the atmosphere, called the ionosphere, has made great progress. It is now known that several distinct layers of ionization exist. The first, called the $E$ layer, is at a height of about sixty miles and is capable of reflecting fairly long waves. The second, called the $F_{1}$ layer, is capable of reflecting shorter waves, at a height of about 120 miles, and the third, the $F_{2}$ layer, reflects still shorter waves at a height of about 180 miles. The ability of these layers to reflect radio waves depends on the number of electrified particles present, either electrons or electrified air molecules. In an article communicated to the Radio Review of Australia of June by a member of the staff of the Carnegie Institution, it is described how the ionosphere affects radio transmission.

The author refers to the recent discovery by Dr. J. B. Dellinger, of the U.S. Bureau of Standards, of sudden fade-outs of high-frequency radio signals on the daylight side of the earth, and that these fade-outs were connected with the hydrogen prominences which sometimes appear on the sun. It is believed that all these fade-outs occur simultaneously with solar eruptions. When a fade-out occurs, no reflections are obtained from the $E, F$ or $F_{1}$ layers. It is just as if one were looking into a looking glass and suddenly the reflection disappeared. The cloud of electrons which prevent the waves being transmitted may be considered as a 'blanket' covering the entire daylight hemisphere of the earth at a height of $40-60$ miles.

A very pronounced fade-out occurred in April 1936 ; a sudden brightening was observed in the region around a spot on the sun. One minute later radio reflections from the ionosphere ceased and a large change also occurred in the earth's magnetism and in the earth currents. The heights of the reflecting layers recorded at the Carnegie Institution's observatories in Peru and Western Australia and by other organizations, serve to indicate the nature of the effects produced.
The improved quality of the ionosphere during times of sunspot activity makes a greater range of wave-lengths available for long-distance transmission. Unfortunately, times of sunspot maximum are most favourable for the occurrence of magnetic storms. These storms are believed to be due to swarms of ions and neutral corpuscles ejected from the sun with such speed that they reach the earth in about a day. Impinging on the atmosphere, these corpuscles give rise to auroral displays in high latitudes and seriously impair radio communication, when the path of the radio waves passes close to the radio zone--a region about $20^{\circ}$ from the geo-magnetic pole. Most of the radio traffic between the United States and Europe traverses such a path, with the result that on days of great magnetic disturbances those radio circuits are never available.

On the other hand, radio traffic between the United States and points in South America is not seriously impaired by magnetic disturbance. An ingenious application of this fact was made by one of the commercial companies during the severe magnetic disturbances on April 24-28, 1937. Radio messages intended for European points were 'routed' through the company's station in South America and retransmitted to Europe, with the result that communication was maintained throughout the disturbance.

Another interesting application of scientific knowledge concerns the scheduling of trans-Atlantic broadcast programmes. Research has shown that times of magnetic disturbances tend to recur at 27-day intervals, corresponding to the period of rotation of the sun. On this basis, it is possible to predict a month or two in advance the days that are likely to be unsatisfactory for long-distance transmission and the days that are likely to be satisfactory. International broadcasts, scheduled for pick-up by one of the large networks, are arranged so far as possible to come when no magnetic storms are expected.

The means by which magnetic storms affect radio transmission is not clearly understood. The effects of magnetic storms on radio transmission are markedly different from the effects produced by the ultraviolet light from solar prominences. While storm effects are most strongly manifested in high latitudes, the fade-outs are most pronounced near the equator. Furthermore, the fade-outs occur only during day. light hours, while the storms disturb radio transmission on both the day and the night sides of the earth. 